\title{
Foreword - the DMRB and structures standards
}

Mike Wilson BEng, CEng, FICE, FCIHT

Chief Engineer, Highways England, UK

As chief engineer of Highways England, I was delighted to be asked to write a foreword to this special issue of Bridge Engineering.

When Highways England (HE) was established in 2015, the need for a review and update of its standards was one of the key requirements and was set out in the licence arrangements. The Design Manual for Road and Bridges (DMRB), containing all of HE's standards, has an enviable position and is widely regarded. However, it was apparent that it was becoming out of date and in need of a thorough overhaul.

The DMRB is used by many UK highway authorities, as well as the devolved administrations in Scotland, Northern Ireland and Wales. It has commanded considerable respect and is complementary to British and European standards. Bringing the HE documents up to date ensured that they reflect current good practice, taking on board the latest research and enabling innovation. Most importantly, the documents are now published in a consistent format, bringing much improved clarity of requirements, along with associated guidance. This will help drive savings and efficiencies in contracts. HE has also taken the opportunity to embrace the latest digital publishing arrangements, which means that the DMRB and individual documents can keep pace with the ever-changing world of design and construction.

The structures standards are the largest section of the DMRB, formerly occupying volumes 1,2 and 3 . The review and update has been a huge exercise for all those involved. I must record my thanks to all the HE document owners, those authoring the updates and all the industry contributors to the peer review process through technical project boards drawn from the devolved administrations, designers, contractors, manufacturers and many construction industry organisations. This was a significant collaborative effort by all.

I hope that you will find the accompanying papers both interesting and informative. They were written by HE structures engineers and consultants who undertook the drafting of the revised structural documents. The topics were selected based on their usage and where there have been significant technical changes. Structural assessment is a key area and is reflected in a suite of linked documents. The management of vulnerable structures (such as post-tensioned bridges and those with hinge and half-joint decks) and structures subject to hydraulic actions is described in the following papers. Particularly important are the new requirements for concrete repair and the associated specification clauses. This special issue also provides an overview article covering the background to the DMRB review in more detail, together with shorter summaries of technical changes in various other documents. HE welcomes feedback for the future development of these new documents.

However, the structures documents are only part of the story HE has been extremely busy reviewing and updating the full suite of documents, be they for pavements, drainage, geotechnics, vehicle restraints and the environment as well as road layout requirements. We expect that the current published documents represent just the start of the journey to ensure that the DMRB is always fit for the future. 